\title{
ANÁLISIS COMPETENCIAL DE LA ESCRITURA ACADÉMICA EN ESPAÑOL LENGUA EXTRANJERA (ELE) DE ESTUDIANTES PORTUGUESES.
}

\section{COMPETENTIAL ANALYSIS OF ACADEMIC WRITING OF PORTUGUESE STUDENTS OF SPANISH FOREIGN LANGUAGE (SFL)}

\author{
Ester Trigo lbáñez \\ Xaquín Núñez Sabarís
}

\section{Resumen}

El presente trabajo analiza las capacidades y estrategias de un grupo de 36 estudiantes universitarios portugueses al afrontar una práctica de escritura académica en español lengua extranjera (ELE). La investigación, realizada en el Instituto de Letras e Ciências Humanas de Braga durante el mes de abril de 2018, surge de un convenio de colaboración, en el marco de la estrategia Erasmus + Ka-103, entre la Universidad de Cádiz y la Universidade do Minho. El diagnóstico ha aportado información sobre los procesos cognitivos inherentes a la actividad escritora en ELE. Para su realización, se han utilizado una serie de rúbricas, validadas en investigaciones precedentes, que han permitido analizar cualitativamente los niveles competenciales en los que se sitúan los estudiantes participantes. Los hallazgos han evidenciado la necesidad de plantear 
estrategias institucionales conducentes a mejorar tanto los procesos de escritura académica como la enseñanza y aprendizaje de la lengua meta.

\section{Palabras Clave}

Alfabetización académica, escritura académica, ELE, didáctica de la lengua, enseñanza de lenguas.

\section{Abstract}

This work analyses the activated capacities and strategies of a group of 36 Portuguese undergraduate students when facing an academic writing practice in Spanish as a foreign language (SFL). The research, carried out at the Institute of Letters and Human Sciences of Braga during the month of April 2018, arises from a collaboration agreement, within the framework of the Erasmus + Ka-103 strategy, between the University of Cadiz and the University of Minho. The diagnosis has provided information about the cognitive processes inherent in the writing activity in SFL. For its implementation, we have employed a series of rubrics, validated in previous investigations, that have permitted us to analyse qualitatively the competence levels in which participating students are located. The findings have shown the need to propose institutional strategies able to improve both the processes of academic writing and the teaching and learning of the target language.

\section{Key Words}

Academic literacy, academic writing, SFL, language teaching.

\section{Introducción}

La práctica de la escritura académica es una actividad constante en la vida de todo estudiante universitario. Durante sus estudios, se enfrenta a distintas prácticas letradas en las que ha de demostrar solvencia en la escritura de diversidad de géneros textuales. Pero la frecuencia de uso no supone una garantía de éxito, cuestión que ha sido ampliamente discutida (Parodi, 2000; Ballano \& Muñoz, 2015; Romero, 2015). Prueba de ello es el 
estudio de Gutiérrez-Rodríguez \& Flórez-Romero (2011), acerca de los saberes y prácticas docentes y estudiantes sobre escritura académica en el contexto universitario, donde se detecta un desfase entre el deseo y la realidad: un $83 \%$ de los docentes universitarios manifiesta que las personas que acceden a la universidad deberían saber escribir. Sin embargo, el $67 \%$ opina que los estudiantes no dominan esta destreza.

Y es que afrontar la escritura académica no es una empresa fácil pues, como señalan Camps \& Castelló (2013) el discurso académico "no es simplemente el vehículo por donde transitan los saberes, sino que es un instrumento de construcción del conocimiento y de las relaciones que establece con las actividades humanas en que se desarrolla" (p. 18). Por ello, la sociedad actual, en general, y la Universidad, en particular, vienen demandando una ciudadanía competente al transmitir el conocimiento. Bajo esta idea, Romero (2014) concibe la expresión escrita como:

la transferencia y concreción del pensamiento en un texto donde confluyen las propias capacidades del individuo: unas estrategias de elaboración que combinan tanto aspectos cognitivos (desde la planificación a los diversos momentos de revisión, como garantías de una correcta textualización de nuestra escritura), como psicomotrices (que redundarán en la mejora de la edición y presentación) del escrito y comunicativos (la intención y la finalidad del escrito, el registro, la extensión o los aspectos formales) (p. 9).

Ante estos planteamientos, como detallan Romero \& Jiménez (2015), surge, en Estados Unidos, una corriente de investigación centrada en la mejora de los procesos de escritura académica (Flower \& Hames, 1981). Estos estudios iniciales han tenido una gran repercusión y han generado una prolija línea de trabajo (Cassany, 1987; Álvarez, 2010; Jiménez \& Romero, 2012; Romero, 2014; Gutiérrez, 2014; Parodi, 2015, entre otros).

Sin embargo, al concebir, como Teberosky (2007) el texto académico como una construcción, producto de un acto comunicativo, que posee textura y finitud, consideramos que para mejorar los procesos de escritura es necesario que los docentes y los estudiantes sean conscientes de las estructuras jerárquicas que conforman un determinado texto y de las sub-destrezas que deben activarse al escribir bien (Kruse, 
2013; Romero, 2015). Precisamente amparada en esta razón surge la preocupación del Departamento de Didáctica de la Universidad de Cádiz por determinar el perfil de ingreso de los estudiantes que acceden a los grados de magisterio (Romero, 2014; Jiménez, Romero \& Trigo, 2014; Romero \& Jiménez, 2015) para diseñar actuaciones, dentro del plan de estudios, dedicadas a la enseñanza de la escritura académica (Romero, Salvadro, Trigo, 2014).

Pero esta preocupación no se ciñe solamente al contexto de la universidad de Cádiz, sino que trasciende a otras etapas y contextos educativos -a partir de las indagaciones realizadas en los procesos de formación permanente del profesorado(Romero \& Trigo, 2015; Romero \& Trigo, 2018) y a territorios internacionales -desde el establecimiento de convenios Erasmus + Ka 103 con las Universidades de Łódź (Polonia) y de Minho (Portugal)- (Romero, 2013).

Es en este contexto de colaboración internacional entre la Universidad de Cádiz y la Univesidade do Minho en el que cobra sentido la presente investigación, que comparte objetivos y metodología con la llevada a cabo por Romero (2013) en la Universidad de Łódź (Polonia). En esta ocasión prestaremos atención al proceso de escritura académica en ELE (Pastor \& Rodríguez-Lifante, 2017) y en cómo la lengua materna portuguesa influye al afrontar una práctica letrada en español (Natel, 2002; Hyland, 2007; Ainciburu, 2013) pues, de acuerdo con Hael (2015):

consideramos que la escritura académica plantea dificultades a estudiantes de grado hablantes de español, por lo que aún puede presentar mayores problemas a personas cuya lengua madre sea otra, inclusive en el caso del portugués, que tiene similitudes gramaticales y lingüísticas con el español (p. 10)

Con ello se pretende, en suma, facilitar información relevante a las instituciones de acogida que pueda derivar en prácticas de evaluación formativa y en la toma de decisiones a la hora de integrar recursos pragmáticos, estrategias metacognitivas y diversidad de actividades y géneros textuales en los programas y diseños curriculares correspondientes. Así, nuestra investigación persigue lo siguiente: 
a) Elaborar un diagnóstico de las capacidades y estrategias que presentan los informantes al realizar una práctica orientada a la escritura académica. Para ello se utilizarán diferentes rúbricas de evaluación analítica que estudiarán los procesos de planificación, textualización y revisión de los escritos presentados.

b) Realizar un análisis contrastivo de los resultados obtenidos tomando como base el concepto de interlengua, desde la lengua materna de los informantes (portugués) hasta la construcción textual en la lengua meta (español).

c) Contribuir a la mejora de los procesos de enseñanza y aprendizaje del español como segunda lengua desde una doble perspectiva. Por un lado, el docente obtendrá una valiosa información para replantear su planificación tras analizar los resultados obtenidos $\mathrm{y}$, por otro, el alumnado al recibir la rúbrica de evaluación, conocerá su nivel de desempeño y podrá trazar su hoja de ruta hacia la consolidación del proceso de escritura académica.

d) Abrir un foro de discusión, manifiesto en una matriz DAFO, sobre los factores internos -debilidades y fortalezas- y externos -amenazas y oportunidadesque atañen a la escritura académica en contextos universitarios.

\section{Método}

Esta investigación se realizó durante el curso 2017-2018, momento en el que se hace efectiva la movilidad Erasmus + Ka 103 desde la Universidad de Cádiz a la Universidade do Minho. Los datos que componen el corpus analizado fueron obtenidos durante la celebración de un seminario sobre escritura académica, impartido por la profesora Ester Trigo Ibáñez. La muestra de estudio se conformó de 36 estudiantes del Instituto de Letras e Ciências Humanas de la Universidade do Minho, que accedieron voluntariamente a la realización de la prueba. Estos estudiantes proceden de las asignaturas "Língua II.6 - Espanhol B2+", integradas en el sexto semestre de dos licenciaturas Línguas Aplicadas y Línguas e Literaturas Europeias. ${ }^{1}$ 
Las pautas metodológicas se corresponden con las marcadas por Romero (2013, pp. 166-168). En este sentido, se ha seguido un procedimiento análogo en la realización de la prueba, se han utilizado las mismas rúbricas de evaluación y variables de estudio.

La prueba, con carácter abierto para poder realizar un primer estudio cuantitativo y un posterior análisis cualitativo de las variables (Romero, 2013; Romero \& Jiménez, 2015), consistió en el visionado de un documento, de nueve minutos de duración, titulado Aprender a enseñar. Profesión profesores, incluido en el programa de la televisión andaluza TESIS?.

La selección de este fragmento se justificó por dos razones: su temática, dado que se trataba de estudiantes de ELE, debía proponerse un discurso cercano a los intereses de los estudiantes y adecuado a los descriptores de su nivel de referencia; y su estructura, puesto que se corresponde con un discurso, a modo de conferencia, al que los estudiantes se enfrentan constantemente.

Antes de realizar el visionado, se explicó detalladamente la prueba que habrían de realizar. Con ello se aseguraba la comprensión por parte de los estudiantes. Así, la primera consigna fue que debían prestar atención a la proyección y tomar apuntes que servirían de base para la realización de un comentario crítico. Tras el visionado, se dio tiempo para que realizaran un esquema -si lo deseaban- que facilitara la realización del escrito final. Seguidamente, se instó a los participantes a escribir su comentario, con una extensión mínima de quince líneas. Finalmente, se dio tiempo para la revisión.

Una vez realizada la prueba, se procedió a su corrección, teniendo en cuenta las siguientes dimensiones: Planificación (toma de apuntes para la generación e ideas y realización de esquema-guion); Textualización (desarrollo textual: adecuación, coherencia, cohesión, léxico; edición textual; legibilidad y espacio entre párrafos), Revisión (ortografía de las letras, ortografía de la acentuación, ortografía de los signos de puntuación). Cada uno de los ítems estudiados se valoró con una rúbrica que oscilaba entre el valor 0 -escaso dominio- y el valor 5 -amplio dominio-. 


\section{Resultados}

Los resultados obtenidos tras el análisis de los datos pretenden servir, como anticipábamos en los objetivos, para mejorar el proceso de enseñanza y aprendizaje de ELE pues tanto el alumnado como el profesorado obtendrá información valiosa de cara a la planificación de los procesos de escritura académica.

Hemos organizado la información en torno a tres dimensiones: Planificación, Textualización y Revisión y a ocho ítems, tal y como reflejamos en la tabla 1, donde aportamos los puntajes medios obtenidos por los 36 informantes. De acuerdo con los resultados generales, los alumnos manifiestan un dominio medio, teniendo en cuenta que están todavía completando su nivel comunicativo como usuarios independientes (Consejo de Europa, 2002, p. 26), pero con un amplio margen de mejora, en los subprocesos, en concreto en la planificación, que deberá tener un importante impacto en la calidad de la textualización.

\begin{tabular}{lc}
\hline \multicolumn{1}{c}{ Dimensión de análisis } & Puntaje medio $\overline{\mathbf{X}}$ \\
\hline Dimensión 1: Planificación & 1,8 \\
\hline Ítem 1: Esquema-guion & \\
\hline Dimensión 2: Textualización & 2,4 \\
\hline İtem 2: Desarrollo textual & 3,4 \\
\hline Ítem 3: Adecuación textual & 3,2 \\
\hline İtem 4: Legibilidad & 3,8 \\
\hline İtem 5: Espacio entre párrafos & \\
\hline Dimensión 3: Revisión & 3,5 \\
\hline İtem 6: Ortografía de las letras & 2,9 \\
\hline İtem 7: Ortografía de la acentuación & 2,5 \\
\hline Ítem 8: Ortografía de los signos de puntuación & 2,9 \\
\hline Prueba completa
\end{tabular}

Tabla 1. Puntajes medios obtenidos en cada ítem. Fuente: elaboración propia

Vamos a detenernos ahora en analizar pormenorizadamente los resultados de cada dimensión. Así, ilustraremos con ejemplos concretos que servirán como base reflexiva para trazar propuestas de actuación encaminadas a la mejora de los subprocesos de producción textual y a determinar un posible perfil del escritor (Ruiz, 2009; Romero, 2015).

\section{a.Dimensión 1: Planificación}


Como se ha podido apreciar en la tabla 1, los informantes, a pesar de que el $75 \%$ de ellos (27 de 36 ) toma apuntes durante el visionado, no planifican debidamente la producción textual. De hecho, como refleja el gráfico 1, 22 estudiantes no realizan un esquema previo como base para abordar la práctica letrada. Tan solo 3 informantes realizan un guion con información jerarquizada, pero ninguno de ellos organiza correctamente sus ideas respetando una esperable progresión temática.

Es llamativo el caso del informante 06 que, al no elaborar un borrador que le sirva como base para el desarrollo del comentario crítico, en su escrito final encuentra necesario realizar una nota aclaratoria "*Entonces el cambio en el sistema educativo es extremadamente necesario" para hacer comprensible su discurso.

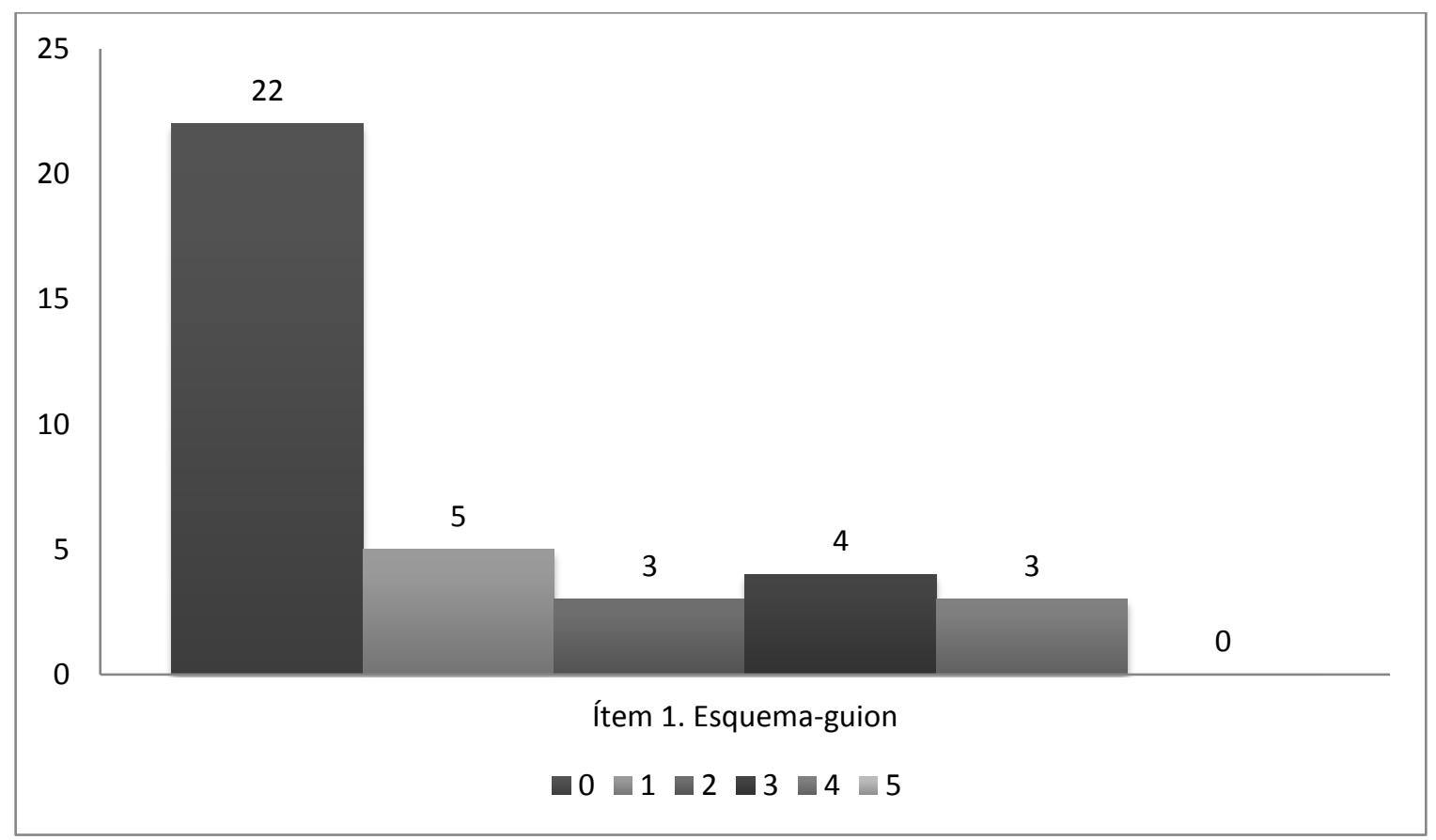

Gráfico 1: Distribución de los informantes según su nivel de desempeño en la realización del esquema-guion

\section{b.Dimensión 2: Textualización}

En este apartado tendremos en cuenta, por un lado, los aspectos relacionados con el desarrollo textual: la adecuación, coherencia y cohesión y, por otro, los que atañen a la edición del texto: la legibilidad y el espacio entre párrafos (ítems 2, 3, 4 y 5). 
$\mathrm{Si}$ atendemos al desarrollo textual -ítem 2-, comprobaremos que, en líneas generales, los estudiantes, están todavía en fase de consolidación del nivel de conocimiento de la lengua meta en temas y actividades comunicativas complejas, como la práctica orientada a los trabajos académicos en español. Sin embargo, aunque no se alcanzan niveles muy altos, los informantes demuestran cierto dominio en la edición del texto - vid. Tabla $1-$.

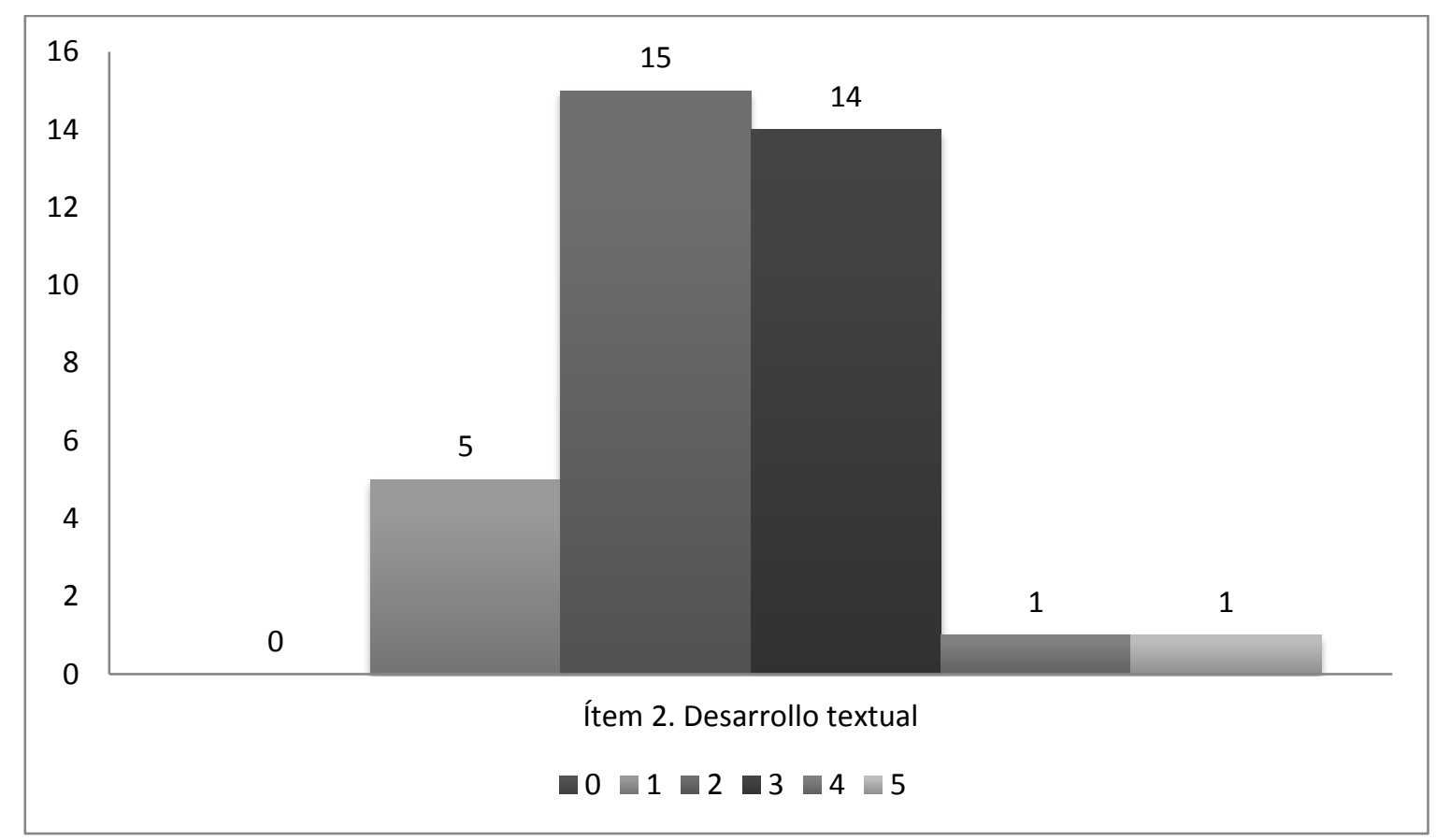

Gráfico 2: Distribución de los informantes según su nivel de desempeño en el desarrollo textual

El gráfico 2 muestra que la mayoría de los informantes manifiestan un desempeño irregular y todavía vacilante al realizar la práctica letrada pues, en general, tienen dificultades en construir textos totalmente estructurados y cohesionados y, en su mayoría no consignan una diferenciación clara de ideas por párrafo. Tan solo detectamos un estudiante que alcanza la excelencia pues, como refleja la tabla 2, presenta un escrito bien estructurado, cohesionado, fundamentado, creativo y original.

\begin{tabular}{|c|c|}
\hline \multicolumn{2}{|r|}{ DESARROLLO TEXTUAL } \\
\hline & $\begin{array}{l}\text { Si además, el texto está escrito de una manera creativa y original tanto por su contenido } \\
\text { como por su correcta expresión. }\end{array}$ \\
\hline & $\begin{array}{l}\text { El texto presenta una estructura clara y y y adecuada } \\
\text { (PLANTEAMIENTO/INTRODUCCIÓN, DESARROLLO Y CIERRE/CONCLUSIÓN) y plantea los } \\
\text { párrafos de manera fundamentada (con datos, citas, autores, opinión personal...) y cohesionada } \\
\text { (empleo de conectores textuales). }\end{array}$ \\
\hline & $\begin{array}{l}\text { El texto presenta una expresión precisa aunque poco fundamentada; además, no se } \\
\text { observan de manera clara la cohesión entre las diferentes partes del texto (no emplea conectores } \\
\text { textuales). }\end{array}$ \\
\hline
\end{tabular}




\begin{tabular}{c|c}
\hline & La estructura no es clara y no hay diferenciación de párrafos en el desarrollo de las \\
\hline & Escribe el texto mediante un solo párrafo sin diferenciar las ideas. \\
\hline & No realiza el comentario. \\
\hline Tabla 2. Rúbrica de evaluación del ítem 2: desarrollo textual
\end{tabular}

En lo concerniente a la adecuación textual -ítem 3-, observamos, según indican la tabla 3 y el gráfico 3, que 30 de los 36 informantes aporta un léxico no especializado, en ocasiones impropio y con frecuentes marcas de oralidad y expresiones coloquiales. Tan solo seis informantes utilizan un registro adecuado y un léxico especializado. Es en este apartado en el que detectamos mayor dificultad por parte de los estudiantes para "adaptarse a una situación comunicativa concreta en lengua extranjera, haciendo hincapié en el registro idiomático y en el nivel de especialización del léxico en relación con dicha situación" (Romero, 2013, p. 174).

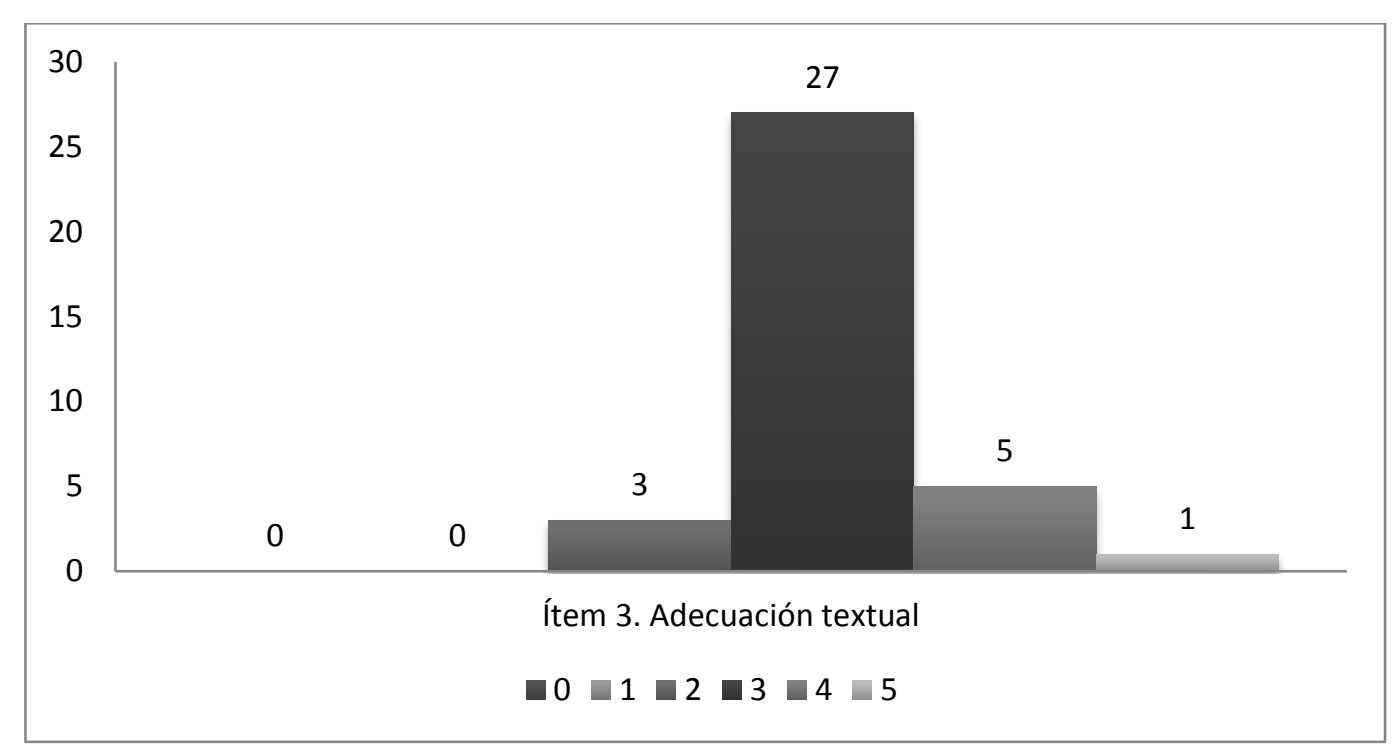

Gráfico 3: Distribución de los informantes según su nivel de desempeño en la adecuación textual

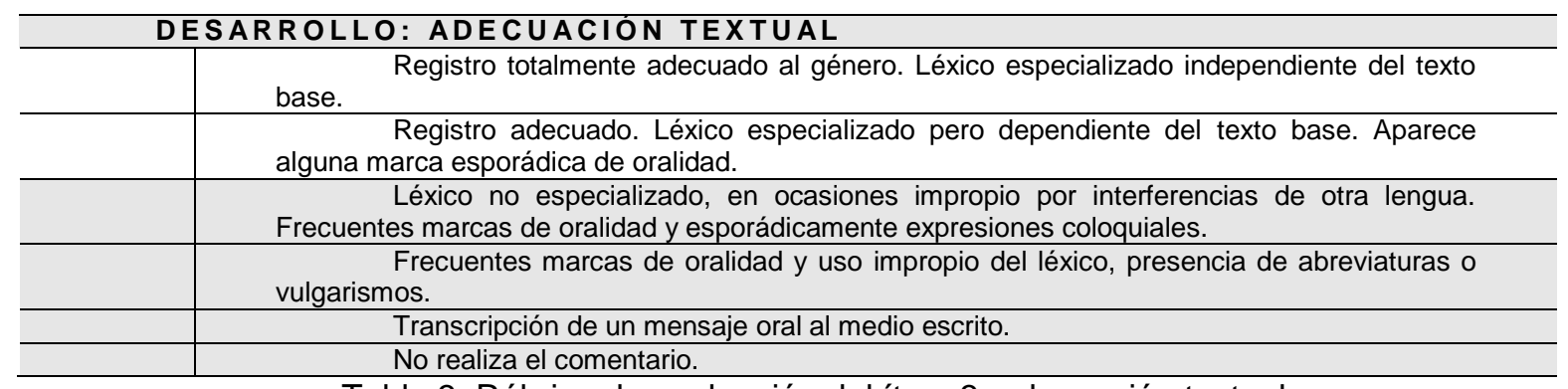

Tabla 3. Rúbrica de evaluación del ítem 3: adecuación textual

Dado que hemos detectado un alto grado de influencia de la lengua materna de los informantes -portugués- sobre la lengua meta -español-, hemos realizado una 
clasificación de los fenómenos léxicos y gramaticales que podrían "orientarnos a una didáctica distinta que tenga en cuenta los conocimientos previos de los aprendices y la proximidad entre portugués y español como aliados" (Natel, 2002, p. 831). Además, el conocimiento de los errores más frecuentes ayudará a los docentes a trabajar desde el error pues, como advierte Pérez (2007) corremos el peligro de situarnos en "una interlengua llena de errores fosilizados muy difíciles de eliminar si no existe interés ni esfuerzo para superarlos" (p. 29). La siguiente indicación de las alteraciones léxicas y gramaticales no persigue todavía una jerarquización y evaluación, en relación con los procesos de adquisición de la lengua meta, sino una constatación de las incidencias que permita encarar el error como un instrumento indispensable de la evaluación formativa del alumno.

Así, en el plano léxico consignamos lo siguiente:

"No sufría ninguna mudanza [cambio]" (I_0533, I_18); "focarse [enfocarse]" (I_13); "moldan [amoldan]" (I_15); "perca [pierda]" (I_16); "obrigaciones [obligaciones]" (I_16); "ensino [enseñanza]" (I_16, I_25; I_26); "ensiñado [enseñado]" (I_27, I_34); "demostre [demuestre]"; "mejoramientos [mejoras]" (I_07; I_20); "evoluir [evolucionar]" (I_23); "inovar [innovar]" (I_07); "crescan [crezcan]" (I_31) "permiter [permitir]" (I_16); "rates [retos]"; (1_28) "debría [debería]" (I_36); busca [búsqueda] (I_22); "un abrir de ojos [un abrir y cerrar de ojos]” (I_01), “ideia [idea]” (I_07).

Y en el plano morfosintáctico:

- Uso del complemento de persona sin preposición a: "servir el país; servir la sociedad" (I_ 09); "no prepara nadie" (I_10); "enseñar los más jóvenes"; "ayude más los jóvenes" (I_07, I_17); "enseñar los niños", "preparar los niños" (I_20); "enseñar los niños" (I_35); "preparar los alumnos (I_32).

- Uso incorrecto del artículo: "con o [lo] que fue dicho" (I_11); "lo sistema (I_12, I_35); “lo profesor” (I_16); “la internet” (I_22, I_23, I_25, I_26, I_27, I_33, I_34)

- No realización de contracción art + prep: "de el [del]" (I_32) 
- Construcción incorrecta de perífrasis verbales: "van formarse" (I_10); van hacer (I_10)

- Uso incorrecto de la conjunción y: "y [e] incluso" (I_13); "diferente y [e] innovadora" (I_19); "e [y] su educación" (I_21); “y [e] informaciones" (I_27)

- Uso del relativo que en lugar de quien o los que: "son los menos talentosos que [los que] acaban enseñando" (I_17).

- Uso del demostrativo estes por estos: "estes deberían tener la iniciativa" (I_19)

- Uso incorrecto de los verbos pronominales: "se reinventar" (I_20); "que se adaptar" (I_24).

- Uso incorrecto de la concordancia: "sus interés" (I_36); "todo la culpa" (I_22); "las clase" (I_24).

- Uso incorrecto de la preposición: "de forma a [en] que” (I_27)

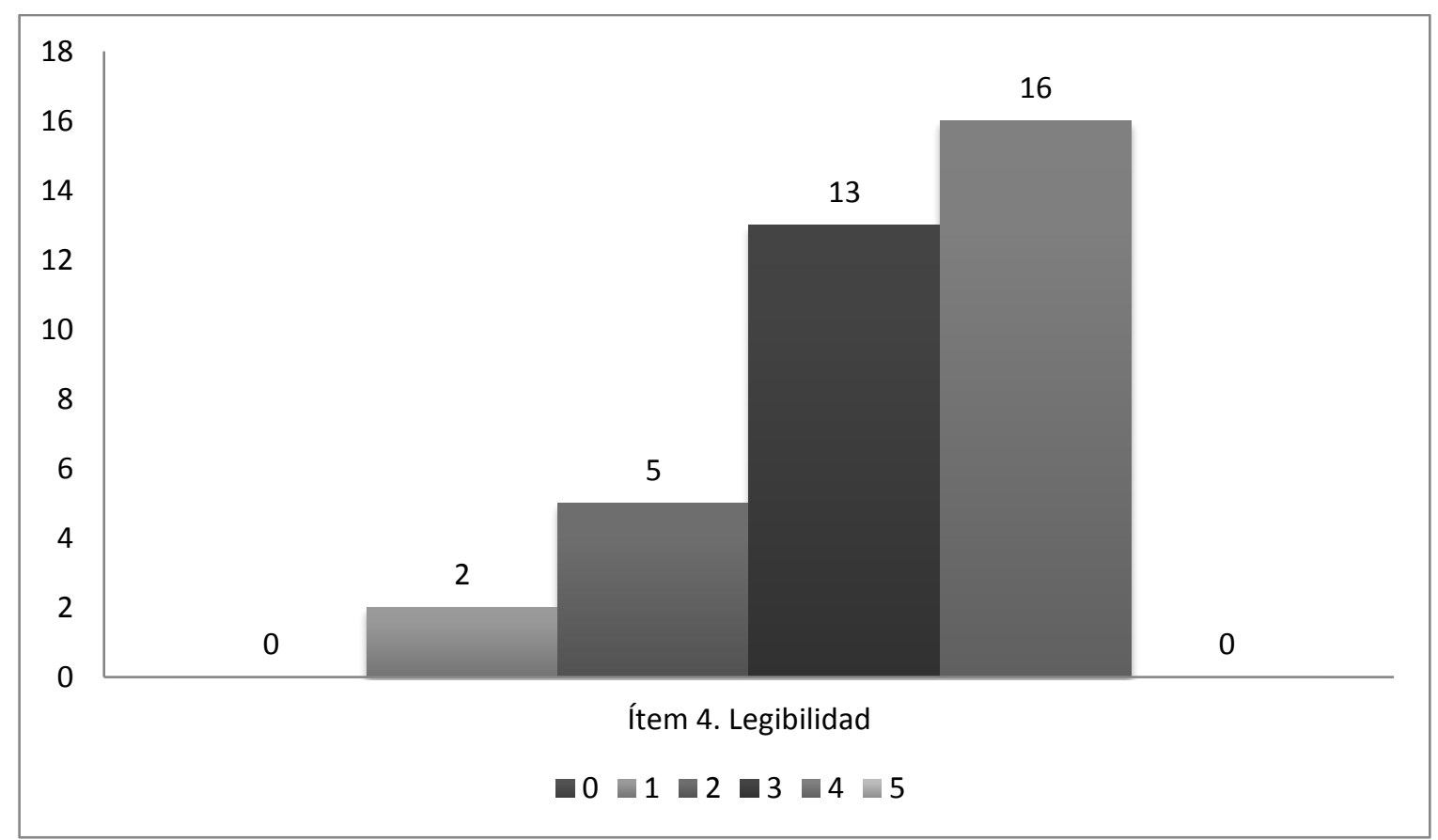

Gráfico 4: Distribución de los informantes según su nivel de desempeño en la legibilidad de la letra

Como se ha reflejado en la tabla 1, la media alcanzada por los informantes en este ítem es de 3,2 puesto que, como se aprecia en el gráfico 4, tan solo 16 de los 36 informantes se sitúan en un nivel de dominio -sin llegar a alcanzar la excelencia- pues utilizan una letra clara y regular, aunque aparecen algunos rasgos no normativos así como 
tachones y correcciones que dificultan la lectura, como es el hecho de realizar todo el comentario crítico en mayúsculas (I_30).

Además, Resulta llamativa la frecuencia de uso de la grafía $R$ como minúscula (I_02, I_04, I_09, I_10, I_19, I_29, I_33, I_34) o el hecho de que dos informantes se refieran a los siglos con números arábigos en lugar de hacerlo con números romanos: "siglo 19 [siglo XIX]" (I_05) o "siglo 21 [siglo XXI]" (I_33).

En la figura 1, a modo de ejemplo ilustrativo, aportamos dos imágenes de comentarios críticos realizados por los estudiantes. El de la parte izquierda está escrito en mayúscula y el de la parte derecha contiene una grafía poco clara y, además, incluye gran cantidad de tachones.

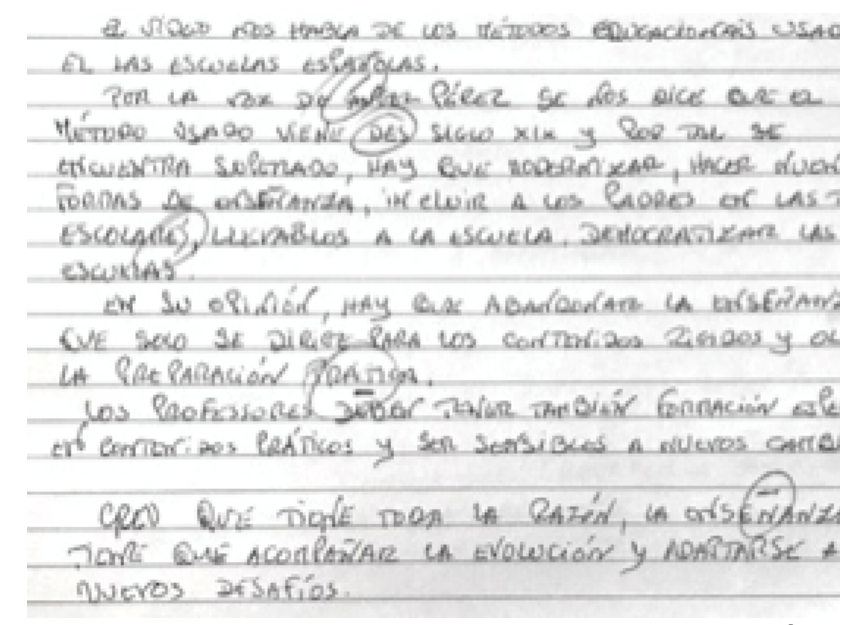

Figura 1. Ejemplo de texto escrito con mayúsculas (I_30) y de mala presentación (I_14)

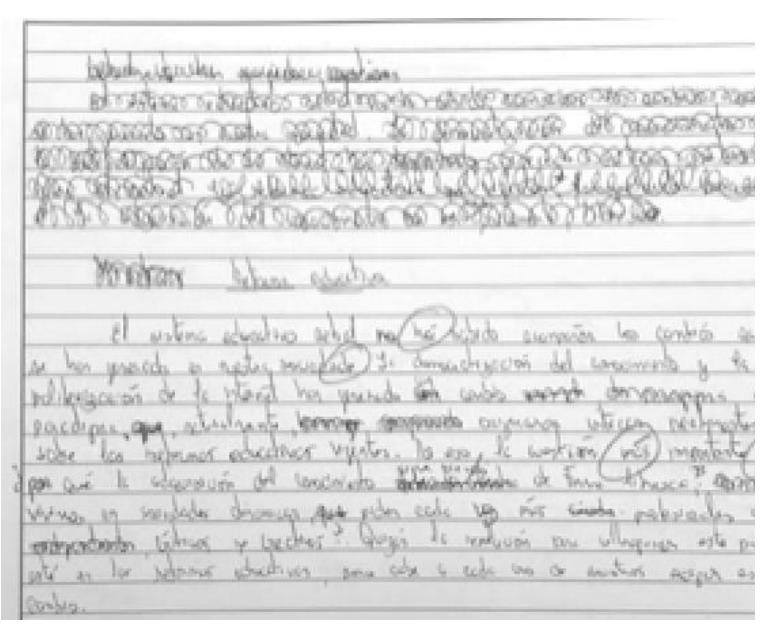

El ítem 5, espacio entre párrafos es el que obtiene un mayor puntaje medio $(3,8)-$ vid. Tabla 1-. 16 de los 36 informantes alcanzan la excelencia, pues utilizan, o bien la sangría, o bien el doble espacio entre párrafos. Sin embargo, en el extremo opuesto, encontramos 6 informantes que escriben todo el texto en un solo párrafo y 8 que no realizan ninguna marca de inicio de párrafo. El resto de informantes realiza un uso irregular de la sangría o doble espacio. 


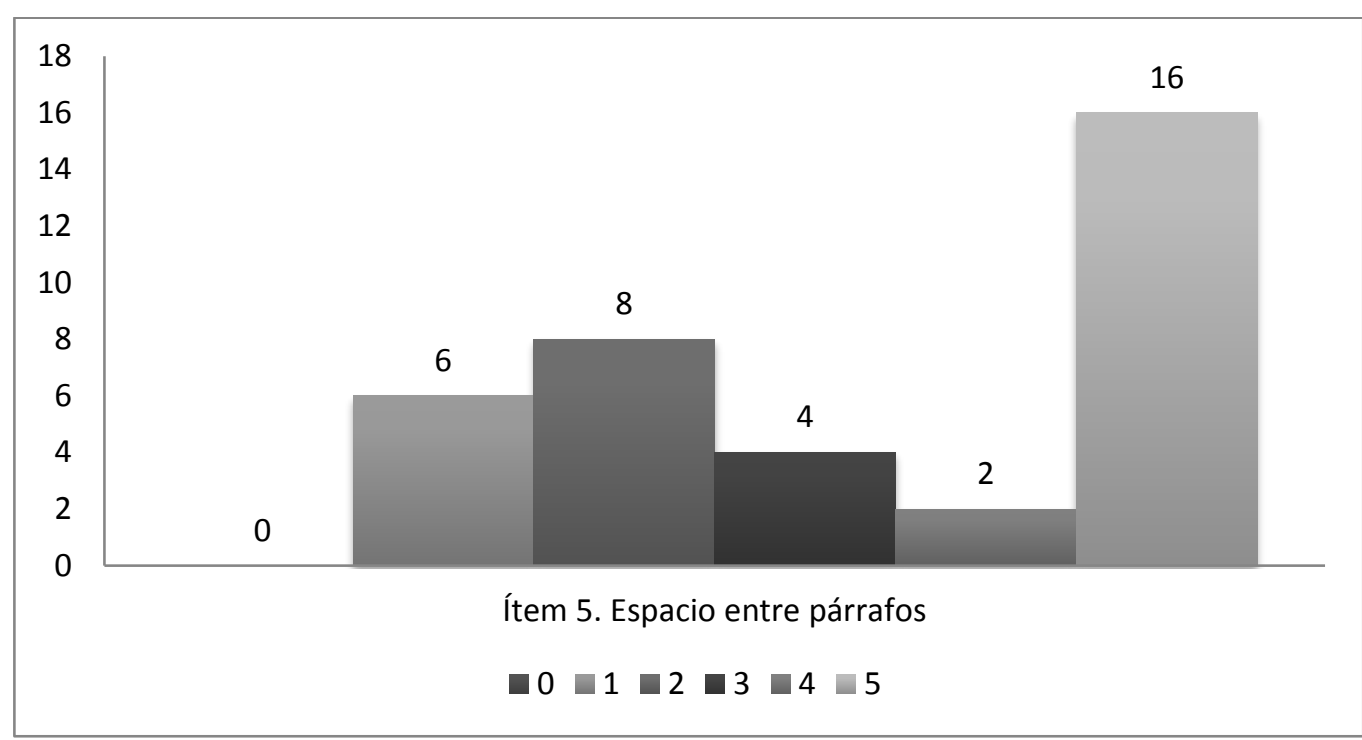

Gráfico 5: Distribución de los informantes según su nivel de desempeño en el espacio entre párrafos

\section{c.Dimensión 3: Revisión}

El hecho de revisar un texto para garantizar que se ha escrito según la normativa ortotipográfica es una cuestión actitudinal (Gómez, 2005). En el proceso de revisión textual se activan "conocimientos para perfeccionar los aspectos normativos y la eficacia de la comunicación" (Romero, 2013, p. 178). En este apartado prestaremos atención a los aspectos ortográficos -ítems 6,7 y 8 -, con especial detenimiento en aquellos errores sustentados en la interlengua.

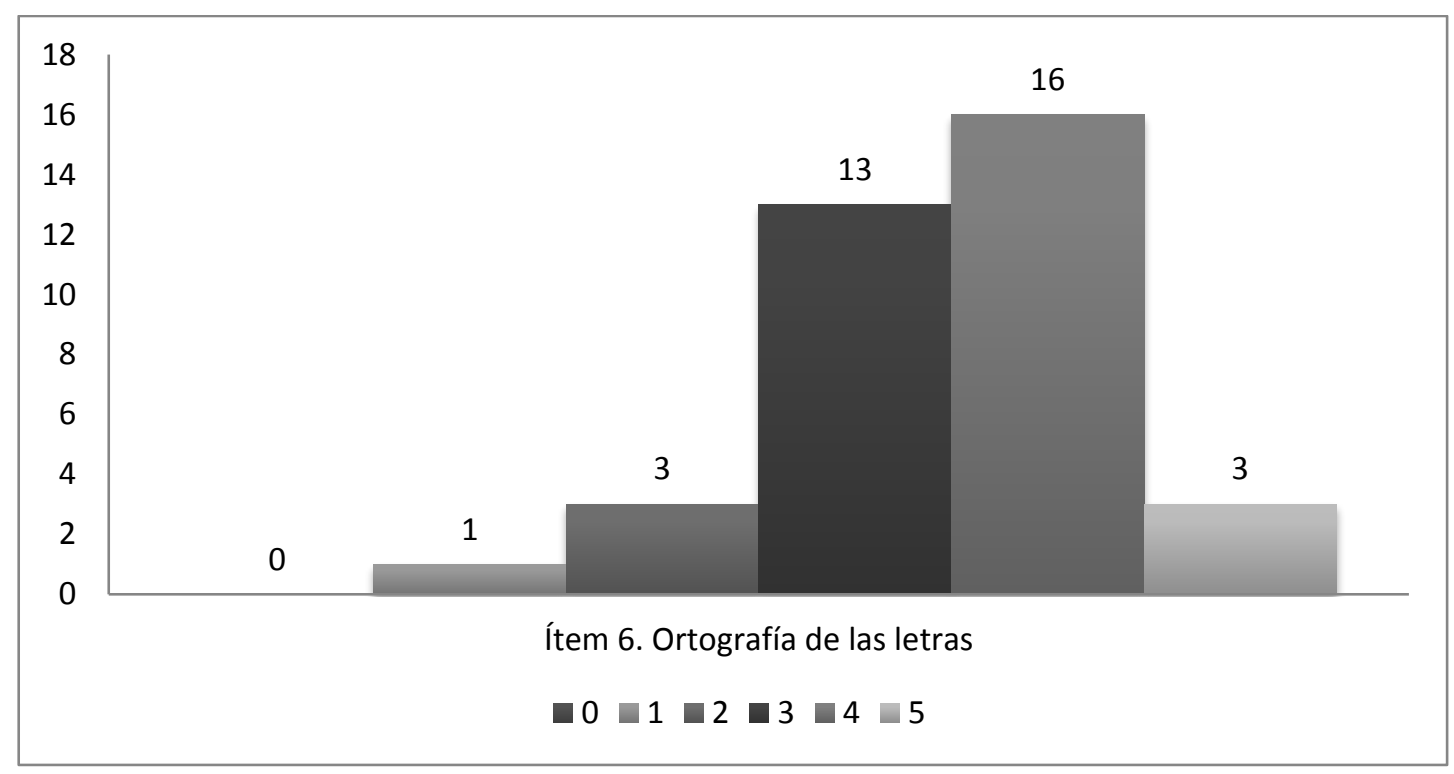

Gráfico 6: Distribución de los informantes según su nivel de dominio de la ortografía de las letras 


\begin{tabular}{l} 
NORMATIVA: ORTOGRAFIA DE LAS LETRAS \\
Dominio bueno: no comete ninguna incorrección en el uso de la \\
\hline ortografía de las letras. \\
\hline Dominio suficiente: solo se detecta algún error puntual. \\
\hline Dominio insuficiente: presenta algunos errores. \\
\hline Dominio muy insuficiente: presenta numerosos errores \\
ortográficos. \\
Dominio muy insuficiente: solo presenta errores de ortografía \\
notural.
\end{tabular}

Tabla 4. Rúbrica de evaluación del ítem 6: ortografía de las letras

En el gráfico 6 se puede observar que, del total de 36 informantes, 17 presenta irregularidades en el dominio ortográfico de las letras, mientras que 18 sí lo hace. El puntaje medio de este ítem - vid. Tabla 1- es de 3,5, lo que, según indica la tabla 4, significa que los informantes presentan errores puntuales al escribir en español, consecuente con los descriptores de la subcompetencia ortográfica en el nivel de referencia de los estudiantes, que todavía señala algunas interferencias de la lengua materna (Consejo de Europa, 2002, p. 115).

Así, encontramos errores de cuatro tipos diferentes:

- Selección de la grafía incorrecta: "Exije [exige]" (I_11); "reproduzir [reproducir]" (I_12, I_19; I_31); “absorver [absorber]" (I_16); “executar [ejecutar]” (I_16); "criatividad [creatividad]" (I_19); “comprobava [comprobaba]" (I_20), "empiezen [empiecen]" (I_34).

- Problemas con las dobles consonantes: "interativo [interactivo] (I_12); "direcionalidad [direccionalidad]" (I_12); “ditan [dictan]" (I_15); "setores [sectores]" (I_18); “direcionada [direccionada]" (I_21); “inovar [innovar]” (I_25); "prática [práctica]" (I_30, I_35); “atitudes [actitudes]" (I_35).

- Adición de vocales: "suspienden [suspenden]" (I_23); "piensamiento [pensamiento]" (I_34).

- Unión de palabras: "talvez [tal vez] (I_29); "porqué [por qué]” (I_35). 


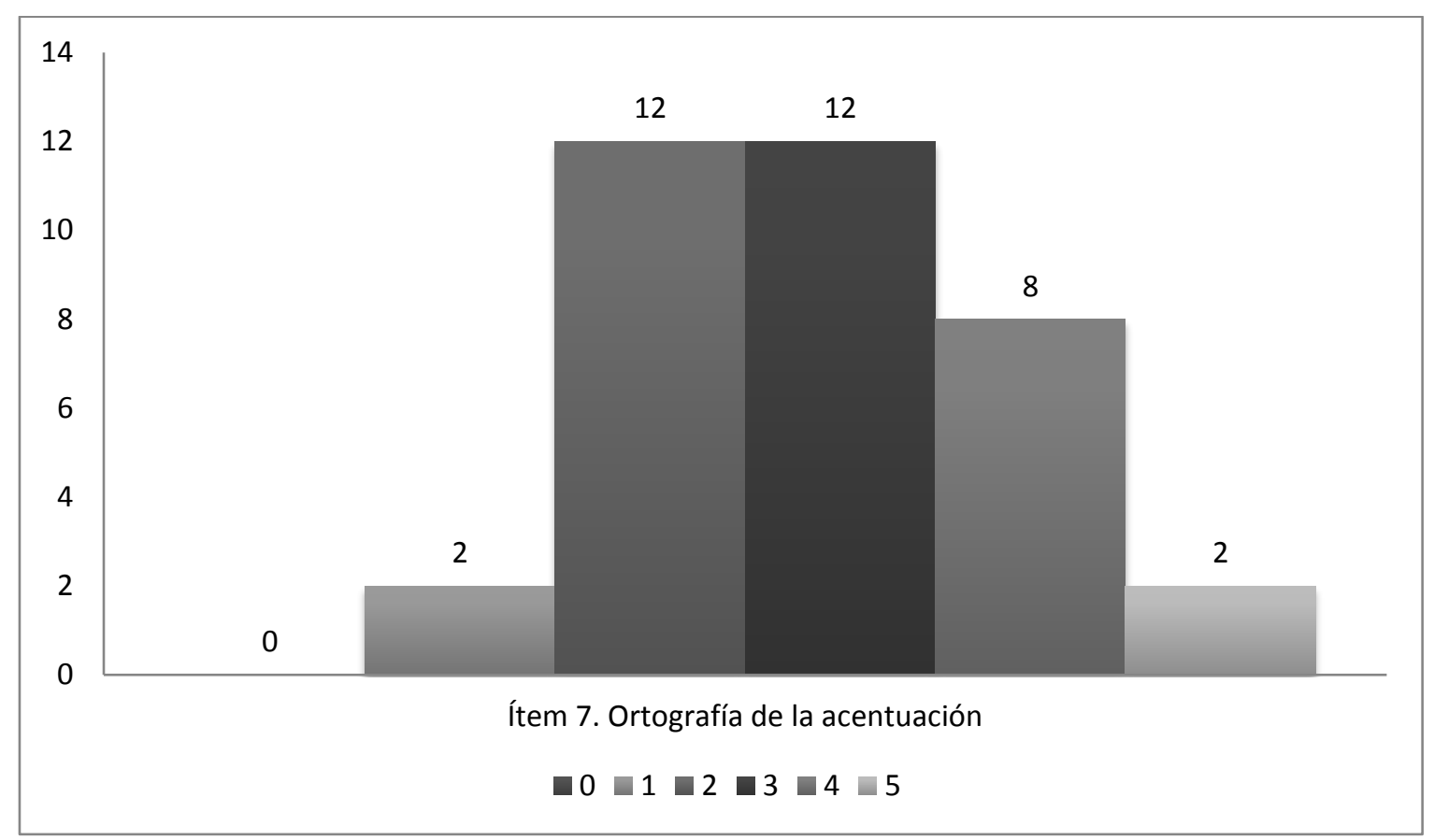

Gráfico 7: Distribución de los informantes según su nivel de dominio de la ortografía de la acentuación

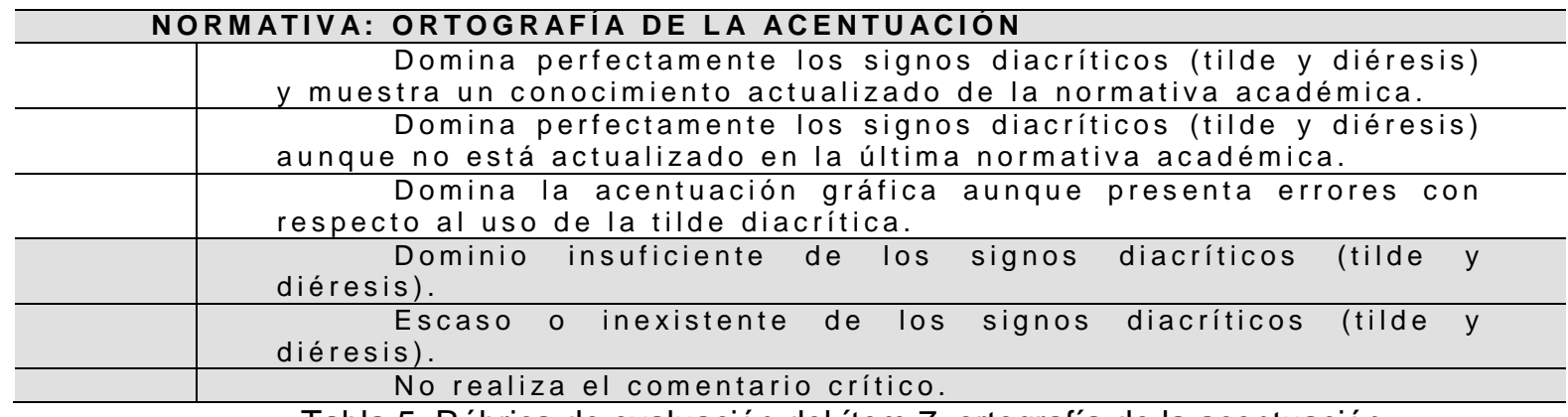

Tabla 5. Rúbrica de evaluación del ítem 7: ortografía de la acentuación

En lo que respecta a la ortografía de la acentuación, como se aprecia en el gráfico 7, tan solo existen dos informantes que alcanzan la excelencia. Sin embargo, la mayor parte de los informantes (24 de 36 ) se sitúan entre los niveles 2 y 3 detallados en la tabla 5 . En este apartado hemos realizado un inventario de errores atendiendo a tres tipologías:

- Adición de tilde cuando la palabra no debe llevarla: "à [a]" (I_01); "há [ha]" (I_14); "és [es] (I_14, I_25); "fué [fue]" (I_16, I_22); “vários [varios]” (I_22); "pués [pues]" (I_23); “matérias [materias]” (I_24); “colégio [colegio]” (I_29).

- No colocación de la tilde cuando la palabra debe llevarla: "iran [irán]" (I_25); "quisieramos [quisiéramos]" (I_26); “contemporaneo [contemporáneo]" (I_27, I_35); “facilmente [fácilmente] (I_29); “Angel [Ángel]” (I_30); “clásico [clásico]" 
(I_34); “contemporaneo [contemporáneo]" (I_34); "metodos [métodos]" (I_35); gramatica [gramática]" (I_35).

- Tilde diacrítica: "como [cómo]" (I_22; I_31; I_32).

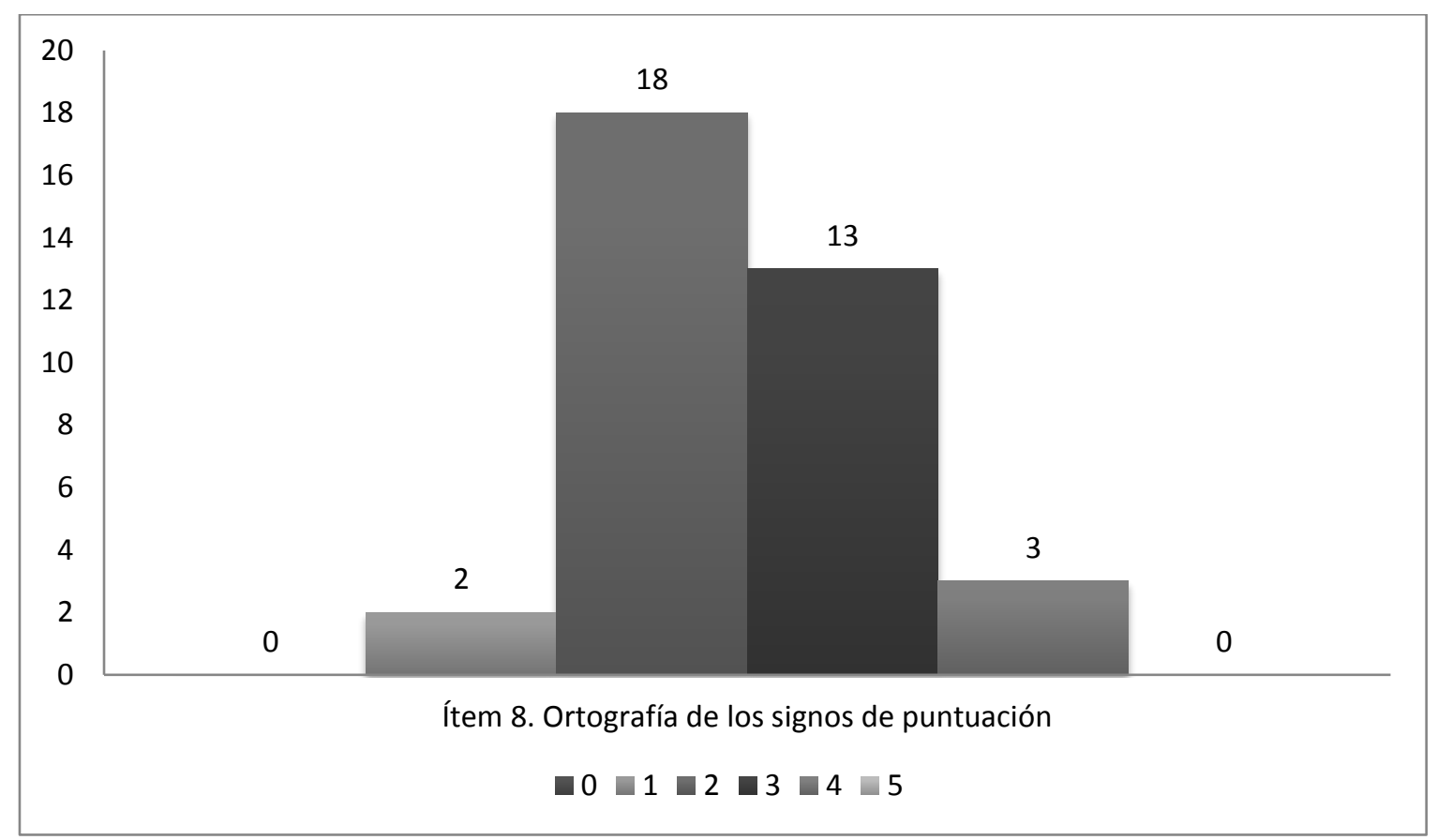

Gráfico 8: Distribución de los informantes según su nivel de dominio de la ortografía de la puntuación

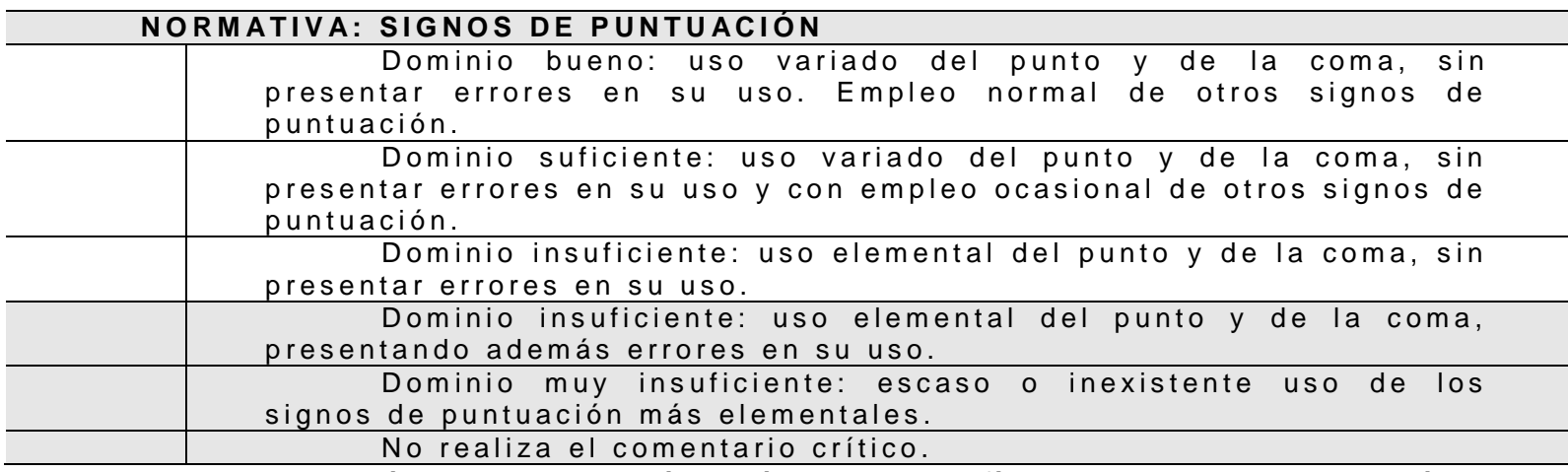

Tabla 6. Rúbrica de evaluación del ítem 8: ortografía de los signos de puntuación

En lo concerniente al ítem 8: ortografía de los signos de puntuación, no se registra ningún informante que demuestre un dominio excelente de este aspecto -vid. Gráfico 8-. La mayor parte de los informantes se sitúan entre el nivel 1 y 2 -20 de 36-detallados en la tabla 6. Por ello, a la vista de estos resultados se hace necesaria, al igual que ocurría en el estudio de Romero (2013) con universitarios polacos "una planificación específica en la enseñanza del idioma" (p. 182). Así, reflejamos, a continuación, algunos errores de uso de 
la coma, a modo de ejemplo ilustrativo. No ha sido posible mostrar casos de uso incorrecto de los dos puntos (:) o del punto y coma (;) puesto que no aparecen en el corpus.

- Falta de coma cuando es necesaria: "Por lo tanto, es necesario innovar, sobre todo [,] porque..." (I_33); "Pate del punto de que [,] aunque muchas veces..." (I_03); "Por eso [,] es necesario que.." (I_10).

- Empleo de la coma entre el sujeto y el verbo: "La primera opinión que fue dada, insiste en que..." (I_01); "la verdad, es que..” (I_25)

\section{Conclusiones}

A lo largo de estas páginas hemos realizado un diagnóstico del desempeño presentado por un grupo de 36 estudiantes portugueses de español al realizar un comentario crítico partiendo del visionado de un programa televisivo. Esta actuación nos ha permitido realizar un pequeño inventario de errores -gramaticales, de propiedad léxica y ortográficos- cuyo origen parece estar en la interlengua del estudiante.

Ya estudios precedentes advertían de las ventajas y los inconvenientes que presentaba aprender español para estudiantes lusófonos (Natel, 2002; Pérez, 2007) y determinaban, entre sus líneas prospectivas, la posibilidad de realizar un listado de posibles errores que permitiera trazar estrategias didácticas encaminadas a la solución de estos. Con nuestra investigación, si bien no contábamos con un corpus muy amplio, hemos querido avanzar en esta idea con la intención de ampliar nuestro campo de estudio en futuras investigaciones para lograr determinar cuáles son los errores, cometidos en español, que tienen como base el hecho de contar con el portugués como lengua materna.

Las rúbricas de evaluación utilizadas habían sido validadas, como detallan Jiménez, Romero \& Sánchez (2014, p. 32) por un equipo de expertos interdisciplinar de los ámbitos de Didáctica de la Lengua y la Literatura y Didáctica de la Organización escolar y utilizadas en estudios realizados con anterioridad por otros investigadores del Departamento de Didáctica de la Lengua de la Universidad de Cádiz en contextos de 
español L1 (Romero \& Jiménez, 2015) y de español L2 (Romero, 2013). Resulta interesante constatar que los resultados obtenidos en esta investigación, realizada con estudiantes portugueses que estudian español como segunda lengua, son coincidentes, en líneas generales, con los hallazgos de Romero \& Jiménez (2015), siendo su contexto de actuación los universitarios españoles de primer curso de los grados de magisterio.

Sin embargo, los informantes polacos del estudio de Romero (2013) manifestaron en el en la realización de esta tarea, un desempeño más alto que los estudiantes españoles y a portugueses, a pesar de la distancia idiomática entre el polaco y el español. Una posible hipótesis quizás radicaría en que suplen esta dificultad con una mayor intensidad en la planificación y revisión, lo que puede redundar en una mayor calidad de la textualización. Convendría, por ello, efectuar un análisis comparativo, de mayor diversidad textual y actuación, que permitiese extraer conclusiones más detalladas acerca del alcance a nivel competencial.

Resultaría, además, de gran interés poder realizar estas investigaciones en otras universidades con las que existe un convenio de colaboración Erasmus + con la universidad de Cádiz y evaluar así la influencia de lenguas próximas al español -italiano o francés- y de lenguas distantes -sueco o inglés-. De esta forma, se podrían contrastar los resultados en dos bloques: español y lenguas próximas; español y lenguas distantes.

El hecho de contar con rúbricas para la realización de una práctica letrada permitirá al estudiante reflexionar sobre los subprocesos de escritura académica: planificación, textualización y revisión para autoevaluar, como propone Romero (2015, pp. 657-658), su propio perfil escritor, teniendo en cuenta los siguientes aspectos:

- Conocimiento de las tipologías textuales.

- Desarrollo de tipologías textuales específicas basadas en discursos académicos.

- Planificación y proceso de revisión textual. 
- Desarrollo y fundamentación de las ideas.

- Pensamiento crítico y proceso de creación basado en la intertextualidad.

- Adecuación y coherencia textual basadas en un dominio del léxico especializado, complejidad sintáctica, ortográfica...

Para finalizar, pretendemos abrir un foro de discusión, a partir de una matriz DAFO en la que evaluaremos factores, internos y externos, negativos -debilidades y amenazas- y positivos -fortalezas y oportunidades-.

\section{DEBILIDADES}

No existe conciencia acerca de la necesidad de planificar la escritura de un texto:

Hay una cultura expresa entre los estudiantes universitarios a la textualización sin los procesos previos que exige una adecuada planificación del escrito, en ocasiones, motivados por la falta previsión y tiempo en la realización de las tareas. (Romero, 2015, p. 647).

Los estudiantes no cuentan con los recursos necesarios para mejorar su escritura:

los manuales de estilo no son suficientes y que se hace relevante introducir cursos específicos en la planificación de cursos de posgrado. (Ainciburu, 2013, p. 81).

El nivel de desempeño de los estudiantes en escritura académica es muy bajo:

Nuestra experiencia docente muestra que los estudiantes universitarios manifiestan carencias muy diversas que no posibilitan la comprensión de lo que escriben. (Romero \& Jiménez, 2015, p. 66)

\section{AMENAZAS}

La proximidad entre el español y el portugués puede ocasionar que el estudiante cometa errores sin ser consciente de ello:

la escritura académica plantea dificultades a estudiantes de grado hablantes de español, por lo que aun puede presentar mayores problemas a personas cuya lengua madre sea otra, inclusive en el caso del portugués, que tiene similitudes gramaticales y lingüísticas con el español (...) consideramos que la expresión formal y escrita en el ámbito universitario requiere de un conocimiento gramatical más completo que otras situaciones de uso de la lengua. (Hael, 2015, p. 10). implicados:

Falta de coordinación entre los agentes

Un programa de escritura no puede diseñarse de manera aislada y cumplir un requisito administrativo. Si pretendemos que funcione satisfactoriamente para ayudar a estudiantes y facultad, la coordinación entre los diferentes agentes implicados -docentes, estudiantes, formadores...- se presenta como una de las claves para el éxito. (Romero, Salvador \& Trigo, 2014, p. 88).
FORTALEZAS

Cada vez contamos con mayor número de universidades preocupadas por la escritura académica que aportan buenas prácticas:

A new dynamic has taken hold of all higher education in Europe with similar problems and similar questions for each country. Whether the solutions will be alike is not yet clear but it is obvious that all countries can only gain from an exchange on their writing policies. We find models for good academic writing not only in the Anglo-Saxon world but also in the various European traditions. What unites the teaching of writing in Europe at the moment are the similarities in the transformation processes with their various stresses and challenges. (Kruse, 2013, p. 38).

Existencia de proyectos institucionales
consolidados encaminados a la mejora de la alfabetización:

Desde esta perspectiva, el equipo del PLC viene asumiendo el desafío de desarrollar la competencia plurilingüe y la competencia pluricultural, consciente de la importancia de los idiomas como parte esencial de la formación integral de las personas. Se trata, pues, de una apuesta específica del Centro que unida a las estrategias de alfabetización académica en lengua española, se fragua en pos del futuro académico y laboral de sus estudiantes. (Romero \& Jiménez, 2015, p. 69). 


\section{Bibliografía}

Ainciburu, C. (2013). Modelos y recursos de escritura académica en diferentes lenguas maternas y su influencia en la práctica ELE. En B. Blecua, S. Borell, B. Crous \& F. Sierra (eds.). Plurilingüismo y enseñanza de ELE en contextos multiculturales (pp. 72-82). XXIII Congreso Internacional ASELE: Universitat de Girona.

Álvarez, T. (2010). Competencias básicas en escritura. Barcelona: Octaedro.

Ballano, I. \& Muñoz, I. (2015). (coords.) La escritura académica en las universidades españolas. Bilbao: DeustoDigital.

Camps, A. \& Castelló, M. (2013). La escritura académica en la universidad. Revista de Docencia Universitaria, 11 (1), 17-36.

Consejo de Europa (2002). Marco Común Europeo de Referencia para las Lenguas. Aprendizaje, Enseñanza, Evaluación. Madrid: Instituto Cervantes-Anaya.

Cassany, D. (1987). Describir el escribir. Cómo se aprende a escribir. Barcelona: Paidós.

Flower, L. \& Hames, J. (1981). A cognitive process theory of writing. College Composition and Communication, 32, 120-160.

Gómez, A. (2005). Enseñar ortografía a universitarios andaluces. Escuela Abierta, 8, 129-147. Gutiérrez, F. (2014). Recursos para el asesoramiento lingüístico de estudiantes univesitarios.

En M. F. Romero \& R. Jiménez (coords.) Hacia una educación lingüística y literaria. Homenaje a los 25 años del Departamento de Didáctica de la Lengua y la Literatura (1987-2012) (pp. 135-141). Cádiz: Editorial UCA.

Gutiérrez-Rodríguez, M. J. \& Flórez-Romero, R. (2011). Enseñar a escribir en la Universidad: saberes y prácticas docentes y estudiantes universitarios. Magis, Revista Internacional de Investigación en Educación, 4 (7), 137-168.

Hael, M. ${ }^{a}$ V. (2015). Escritura académica en lengua extranjera: el caso de estudiantes brasileños en una universidad pública argentina, Signos ELE, 9, 1-24.

Hyland, K. (2007). Genre pedagogy: Language, literacy and L2 writing instruction. Journal of Second Language Writing, 16, 148-164.

Jiménez, R. \& Romero, M. F. (2012). Cómo mejorar la expresión escrita. Manual de redacción para el ámbito universitario. Granada: Grupo Editorial Universitario.

Jiménez, R., Romero, M. F. \& Sánchez, S. (2014). Diagnóstico y evaluación de la 
comunicación escrita en el perfil de ingreso de los grados en Educación Infantil y en Educación Primaria. En M. F. Romero (coord.) La escritura académica: diagnóstico y propuestas de actuación. Una visión desde los grados de magisterio (pp. 25-64). Barcelona: Octaedro.

Jiménez, R., Romero, M. F. \& Trigo, E. (2014). La producción ortográfica en el perfil de ingreso de los alumnos del Grado en Educación Infantil. En M. F. Romero \& R. Jiménez (coords.) Hacia una educación lingüística y literaria. Homenaje a los 25 años del Departamento de Didáctica de la Lengua y la Literatura (1987-2012) (pp. 103-122). Cádiz: Editorial UCA.

Kruse, O. (2013). Perspectives on Academic Writing in European Higher Education: Genres, Practices, and Competences. Revista de Docencia Universitaria, 11 (1), 37-58.

Natel, T. B. (2002). La proximidad entre el portugués y el español, ¿facilita o dificulta el aprendizaje? En M. Pérez \& J. Coloma (eds.). El español, la lengua del mestizaje y la interculturalidad (pp. 825-832). Actas del XIII Congreso Internacional ASELE. Madrid: Centro Virtual Cervantes.

Parodi, G. (2000). La evaluación de la producción de textos escritos argumentativos: una alternativa cognitivo/discursiva. Revista Signos, 33 (47), 151-166. https://dx.doi.org/10.4067/S0718-09342000000100012 (consultado el 3 de mayo de 2018) Parodi, G. (2015). Variation across university genres in seven disciplines: A corpus-based study on academic written Spanish. International Journal of Corpus Linguistics, 24 (4), 469-499.

Pastor, S. \& Rodríguez-Lifante, A. (2017). Español académico a través de la Guía académica para estudiantes internacionales de la Universidad de Alicante. e-AESLA, 3, 99-109.

Pérez, N. (2007). La enseñanza de español a lusohablantes porgueses: ventajas e inconvenientes. En Saz, S. M. (ed.) Actas del XLII Congreso Internacional de la Asociación Europea de Profesores de Español (pp. 27-35). Madrid: Asociación Europea de Profesores de Español (AEPE).

Romero, M. F. (2013). Rasgos competenciales en los (sub)procesos de escritura académica entre estudiantes de español como segunda lengua (ELE). Studia lberystyczne, 12, 165185.

Romero, M. F. (2014). La escritura académica: diagnóstico y propuestas de actuación. Una visión desde los grados de magisterio. Barcelona: Octaedro. 
Romero, M. F. (2015). Autoconcepto y gestión de los (sub)procesos de creación textual en estudiantes universitarios. En X. Núñez, A. González, C. Pazos \& P. Dono. (Coords.). Horizontes científicos y planificación académica en la Didáctica de Lenguas y Literaturas (pp. 641-660). Braga: Ediçoes Húmus.

Romero, M. F. \& Jiménez, R. (2015). La escritura académica como estrategia de centro en la Facultad de Ciencias de la Educación de Cádiz. En I. Ballano \& I. Muñoz (coords.) La escritura académica en las universidades españolas (pp. 63-93) Bilbao: DeustoDigital.

Romero, M. F., Salvador, A. \& Trigo, E. (2014). Propuestas para trabajar la escritura académica en los estudios universitarios. En M. F. Romero (coord.) La escritura académica: diagnóstico y propuestas de actuación. Una visión desde los grados de magisterio (pp. 87-100). Barcelona: Octaedro.

Romero, M. F. \& Trigo, E. (2015). Herramientas para el éxito, Cuadernos de Pedagogía 458, 16-21.

Romero, M. F. \& Trigo, E. (2018). Los proyectos lingüísticos de centro. Desarrollar la comprensión lectora en áreas no lingüísticas. Textos. Didáctica de la Lengua y la Literatura, 79, 51-59.

Ruiz, M. (2009). Evaluación de la lengua escrita y dependencia de lo literal. Barcelona: Graó. Teberosky, A. (2007). El texto académico. En M. Castelló (Coord.) Escribir y comunicarse en contextos científicos y académicos. Conocimientos y estrategias (pp. 17-42). Barcelona: Graó, Barcelona.

\section{REFERENCIA BIBLIOGRÁFICA}

Trigo, E. y Núñez, X. (2018). Análisis competencial de la escritura académica en ELE de estudiantes portugueses. Aula de Encuentro, № 20 (2), pp. 116-139. DOI: https://dx.doi.org/10.17561/ae.v20i2.7 


\title{
Ester Trigo lbáñez es \\ Profesora Ayudante Doctora del Dpto. de Didáctica de la Lengua de la \\ Universidad de Cádiz \\ Correo-e: ester.trigo@uca.es
}

\section{Xaquín Núñez Sabarís es \\ Profesor Titular del Dpto. de Estudos Românicos de la Universidade do Mingho Correo-e: xnunez@ilch.uminho.pt}

\author{
Enviado: 7/05/2018
}

Aceptado: 15/07/2018

Notas:

\footnotetext{
${ }_{1}^{1}$ Ambas licenciaturas persiguen una formación plurilingüe e intercultural, en las que los estudios de español son una de las especialidades. Puede consultarse su plan de estudios en la página web del Instituto de Letras e Ciências Humanas: www.ilch.uminho.pt. Agradecemos a las profesoras María Dolores Lerma Sanchis y Herminda Otero Doval, coordinadoras de ambas asignaturas, las facilidades para el desarrollo del seminario.

2 En el siguiente enlace: https://drive.google.com/open?id=1FEg7iR3oNz1kSmHXhDB1xbvZLcucgi2V se puede acceder al archivo completo.

${ }^{3}$ Hemos codificado los informantes de I_01 a I_36.
} 